\title{
Implementasi Data Mining Menggunakan Algoritma Apriori Untuk Analisis Keranjang Belanja Transaksi Penjualan Pada PT Madu Kembang Joyo
}

\author{
Nasib Ratna Sari Purba ${ }^{1 *}$, Fristi Riandari ${ }^{2}$ \\ ${ }_{1,2}$ STMIK Pelita Nusantara \\ Jl. Iskandar Muda No. 1 Medan 20154 Indonesia \\ Corresponding author‘s e-mail: ratnapurba826@gmail.com
}

\begin{abstract}
Abstrak - Dalam penjualan barang (produk) perusahaan sering mengalami masalah karena tingkat belanja konsumen yang tidak beraturan. Penentuan tata letak produk dilakukan untuk mempermudah konsumen dalam mencari produk madu sehingga tidak mengecewakan para konsumen dalam mencari letak produk mana yang cocok digabungkan dengan produk lain yang sering diminati konsumen, sehingga para konsumen bisa menghemat waktu. Berdasarkan permasalahan yang dihadapi perusahaan, maka dibutuhkan alat bantu analisis data mining. Saat ini pemanfaatan data-data yang dimiliki belum sepenuhnya maksimal, sebatas untuk pembuatan laporan.Masalah penelitian yaitu menumpuknya data transaksi yang tidak dipergunakan, sulitnya meletakkan produk sesuai kebutuhan konsumen. Belum adanya strategi penjualan produk yang efektif. Aplikasi dibangun dengan menggunakan bahasa pemrograman PHP dengan database MySQL. Data yang digunakan untuk analisis keranjang belanja pada transaksi penjualan madu kembang joyo data transaksi 1 bulan. Kombinasi item-item dengan nilai support $\mathrm{x}$ confidence paling tinggi akan dijadikan kombinasi untuk menentukan penempatan letak barang yang cocok dihubungkan antara dua produk yang paling diminati konsumen. Selain itu, kombinasi dari item tersebut dapat digunakan oleh manejemen dalam mengatur posisi produk di dalam rak yang akan memudahkan konsumen menemukan produk yang dibutuhkan.
\end{abstract}

Kata kunci: strategi penjualan, kombinasi item, Data Mining, algoritma Apriori

Abstract - In the sale of goods (products), companies often experience problems because of the irregular level of consumer spending. Determination of product layout is done to make it easier for consumers to find honey products so as not to disappoint consumers in finding the location of which products are suitable to be combined with other products that are often in demand by consumers, so that consumers can save time. Based on the problems faced by the company, data mining analysis tools are needed. Currently, the utilization of data that is owned is not fully maximized, it is limited to making reports. The problem of research is the accumulation of unused transaction data, the difficulty of placing products according to consumer needs. The absence of an effective product sales strategy. The application is built using the PHP programming language with the MySQL database. The data used for shopping cart analysis on the sales transaction of Joyo Flower Honey is 1 month transaction data. The combination of items with the highest support $\mathrm{x}$ confidence value will be used as a combination to determine the placement of the suitable item to be connected between the two products that consumers are most interested in. In addition, the combination of these items can be used by management to position the product on the shelf which will make it easier for consumers to find the product they need. Keywords: sales strategy, item combination, data mining, the Apriori algorithm,

\section{Pendahuluan}

PT Madu Kembang Joyo merupakan perusahaan yang menyajikan produk madu asli, harga terjangkau serta bergaransi. Dimana perusahaan ini setiap harinya harus memenuhi kebutuhan konsumen dan dituntut untuk dapat mengambil keputusan yang tepat dalam menentukan strategi penjualan. Perusahaan ini selalu berusaha memproduksi madu terbaik agar konsumen merasa puas. Dengan jumlah transaksi yang cukup besar, perusahaan membutuhkan alat bantu analisis untuk memberikan informasi yang bermanfaat bagi perusahaan dalam penentuan tata letak barang, produk apa yang paling diminati oleh konsumen dan lain-lain.

Knowledge discovery in database (KDD) didefenisikan sebagai ekstraksi informasi potensial implisit dan tidak dikenal dari sekumpulan data [1]. Proses knowledge discovery in database (KDD) melibatkan hasil proses data mining (proses pengekstrak kecenderungan suatu pola data), kemudian mengubah hasilnya secara akurat menjadi informasi yang mudah dipahami. Dalam teknik data mining terdapat beberapa algoritma untuk menyelesaikannya. Beberapa algoritma tersebut antara lain algoritma hash-based, algoritma apriori dan algoritma FP-Growth [2]. Sedangkan dalam penelitian ini akan menggunakan algoritma apriori. Algoritma apriori merupakan algoritma market basket analysis yang digunakan untuk menghasilkan association rule. Association rule dapat digunakan untuk menemukan hubungan atau sebab akibat. Association rule dapat 
dihasilkan dengan algoritma apriori [3]. Algoritma apriori yang bertujuan untuk menemukan frequent itemsets dijalankan pada sekumpulan data. Market basket analysis merupakan salah satu teknik dari data mining yang mempelajari tentang perilaku kebiasaan konsumen dalam membeli barang secara bersamaan dalam satu waktu [4].

Penelitian penentuan analisis penjualan suku cadang motor menggunakan algoritma apriori dengan judul "Implementasi Analisis Keranjang Belanja Dengan Aturan Asosiasi Menggunakan Algoritma Apriori Pada Perjualan Suku Cadang Motor yang menunjukkan bahwa algoritma apriori cocok digunakan untuk menentukan produk yang dibeli secara bersamaan dengan menggunakan analisa Association [5]. Penelitian analisa pola belanja konsumen pada toko buku gramedia bintaro menggunakan algoritma apriori dapat mencari kombinasi item terbanyak berdasarkan transaksi dan kemudian membentuk pola asosiasi dimana nilai support 11,23\% dan nilai confidence $30,66 \%$.

\section{Tinjauan Pustaka}

2.1. Karakteristik Data Mining

Data mining merupakan proses pencarian pengetahuan yang menarik dari data berukuran besar yang disimpan dalam basis data, data warehouse atau tempat penyimpanan informasi [6][7]. Komponen utama dari arsitektur sistem data mining yaitu [8] [9]:

1. Basis data, data warehouse atau tempat penyimpanan informasi lainnya.

2. Basis data dan data warehouse server, komponen ini bertanggung jawab dalam pengambilan relevant data, berdasarkan permintaan pengguna.

3. Basis pengetahuan, komponen ini merupakan domain knowledge yang digunakan untuk memandu pencarian atau mengevaluasi pola-pola yang dihasilkan. Pengetahuan tersebut meliputi hirarki konsep yang digunakan untuk mengorganisasikan atribut atau nilai atribut ke dalam level abstraksi yang berbeda.

4. Data mining engine, komponen ini terdiri dari modul-modul fungsional data mining seperti karakterisasi, asosiasi, klasifikasi, dan analisis cluster.

5. Modul evaluasi pola, komponen ini menggunakan ukuran-ukuran kemenarikan dan berinteraksi dengan modul data mining dalam pencarian pola-pola menarik.

6. Antarmuka pengguna grafis.

2.2 Algoritma Apriori

Algoritma apriori adalah algoritma yang digunakan untuk mencari frequent itemset yang memenuhi minimal support kemudian mendapatkan rule yang memenuhi minimal confidence dari frequent itemset sebelumnya [10] [11]. Algoritma apriori dibagi menjadi beberapa tahap yang disebut iterasi yaitu [12] [13]:

1. Pembentukan kandidat itemset, kandidat k-itemset dibentuk dari kombinasi (k-1)-itemset yang didapat dari iterasi sebelumnya. Salah satu cara dari algoritma apriori adalah adanya pemangkasan kandidat k-itemset yang subset-nya berisi k-1 item tidak termasuk dalam pola frekuensi tinggi dengan panjang k-1.

2. Penghitungan support dari tiap kandidat k-itemset. Support dari tiap kandidat k-itemset didapat dengan menscan database untuk menghitung jumlah transaksi yang memuat semua item di dalam kandidat kitemset tersebut. Ini adalah juga ciri dari algoritma apriori dimana diperlukan penghitungan dengan scan seluruh database sebanyak k-itemset terpanjang.

\section{Metode Penelitian}

Uraian kerangka kerja penelitian:

a. Analisa Masalah

Pada tahap analisa masalah yaitu melakukan analisa terhadap data yang diperoleh dari penelitian yang telah dilakukan pada tahap pengumpulan data untuk mengetahui permasalahan yang terjadi.

b. Pengumpulan data

Pada tahap ini dilakukan proses pengumpulan data dengan metode wawancara dan observasi untuk melakukan pengamatan dan analisa terhadap sehingga mendapatkan data dan informasi yang dibutuhkan.

c. Penerapan Algoritma Apriori

Pada tahapan ini merupakan suatu proses dimana data transaksi penjualan tersebut diolah dengan menggunakan algoritma apriori. Penerapan algoritma ini merupakan metode yang digunakan dalam penelitian. Dalam penelitian ini algoritma apriori bertujuan untuk menemukan frequent itemset yang dijalankan pada sekumpulan data. Algoritma apriori didefinisikan suatu proses untuk menemukan semua aturan apriori yang memenuhi syarat minimum untuk support dan syarat minimum untuk confidence. Confidence bisa dicari setelah pola frekuensi munculnya sebuah item ditemukan.

d. Perancangan/Pembangunan Sistem 
Pada tahap ini melakukan perancangan sistem yang akan dibangun pada penelitian ini. Rancangan sistem terdiri dari rancangan logika sistem dan interface sistem.

e. Implementasi Sistem

Algoritma apriori bertujuan untuk menemukan frequent itemset yang dijalankan pada sekumpulan data. Algoritma apriori didefinisikan suatu proses untuk menemukan semua aturan apriori yang memenuhi syarat minimum untuk support dan syarat minimum untuk confidence. Confidence bisa dicari setelah pola frekuensi munculnya sebuah item ditemukan.

\section{Hasil dan Pembahasan}

Analisis Kebutuhan Sistem, Pada bagian analisis kebutuhan sistem akan membahas tentang kebutuhankebutuhan sistem yang harus dipenuhi agar sistem berjalan dengan baik. Kebutuhan tersebut adalah sebagai berikut:

1. Aplikasi yang akan dibangun memerlukan data sebagai data input yaitu data transaksi penjualan produk pada Madu Kembang Joyo.

2. Aplikasi yang dibangun mampu mengolah data transaksi penjualan produk Kembang Joyo.

3. Aplikasi yang dibangun menghasilkan informasi yang mampu menentukan pola pembelian konsumen.

4. Aplikasi yang dibangun mampu membantu pihak manajemen dengan memberikan informasi berupa laporan.

Tahapan proses pengolahan data yang dapat dillakukan pada algoritma apriori dengan masukan dari pengolahan data kemudian di proses dalam pembentukan itemset sehingga menghasilkan kombinasi yang terpilih. Tahapan-tahapan algoritma apriori sistem dalam proses data mining adalah sebagai berikut:

1. Menetukan nilai minimum support dan minimum confidence.

2. Menetukan nilai support 1-itemset dan 2-itemset.

3. Menentukan nilai confidence.

4. Pembentukan aturan asosiasi (association rules).

Berikut ini adalah data transaksi penjualan yang terdapat pada PT.Madu Kembang Joyo cabang Cambridge. Data yang diambil adalah data transaksi penjualan produk bulan Januari tahun 2020. Data tersebut adalah data yang mewakili data secara keseluruhan. Data transaksi penjualan diambil dari database sebagai input data yang akan di proses menggunakan algoritma apriori. Data penjualan produk bulan Januari pada Madu Kembang Joyo. Data yang akan dilakukan proses perhitungan algoritma apriori dengan asumsi minimum support $8 \%$ dan minimum confidence $50 \%$ diambil sampel data transaksi.

Analisa Pencarian Pola Frekuensi Tinggi

a. Pola frekuensi 1 itemset

Proses pembentukan support 1 itemset dengan memanfaatkan rumus Support, dimana jumlah minimum nilai support yang ditentukan adalah $8 \%$. Dengan uraian perhitungan sebagai berikut :

Support $(A)=\frac{\sum \text { transaksi mengandung } A}{\sum \text { transaksi }} \times 100 \%$

Support(Bee Pollen Halus 100 gr) $=\frac{4}{28} \times 100 \%=14,29 \%$

Support(Bee Pollen Halus $200 \mathrm{gr}$ ) $=\frac{0}{28} \times 100 \%=0 \%$

Support(Bee Pollen Kasar $100 \mathrm{gr})=\frac{1}{28} \times 100 \%=3,57 \%$

Support(Bee Pollen Kasar 200 gr) $=\frac{1}{28} \times 100 \%=3,57 \%$

Support(Cuka Madu $300 \mathrm{ml})=\frac{3}{28} \times 100 \%=10,71 \%$. "Support" (Cuka Pollen $250 \mathrm{ml}$ )"=" "2" /"28" "x100\%= $7,14 \% "$

Maka produk kombinasi dua item yang memenuhi minimum nilai support yaitu Bee Pollen Halus 100 gr, Madu Hitam 250 ml dan Bee Pollen Halus 100 gr, Madu Kaliandra 660 ml dan Madu Hitam 250 ml, Madu Kaliandra $660 \mathrm{ml}$.

Setelah semua pola frekuensi tinggi ditemukan, barulah dicari aturan asosiasi yang memenuhi syarat minimum untuk confidence dengan menghitung confidence aturan asosiatif $\mathrm{A} \rightarrow \mathrm{B}$. Minimal confidence $=50 \%$

Nilai confidence dari aturan $\mathrm{A} \rightarrow \mathrm{B}$ diperoleh dengan rumus :

Confidence $(\mathrm{A})=\frac{\sum \text { transaksi mengandung A dan B }}{\sum \text { transaksi mengandung } \mathrm{A}} \times 100 \%$ 
Confidence (Bee Pollen Halus $100 \mathrm{gr}$, Madu Hitam $250 \mathrm{ml})=\frac{3}{4} \times 100 \%=75 \%$

Confidence (Bee Pollen Halus $100 \mathrm{gr}$, Madu Kaliandra $660 \mathrm{ml})=\frac{3}{4} \times 100 \%=75 \%$

Confidence (Madu Hitam $250 \mathrm{ml}$, Madu Kaliandra $660 \mathrm{ml})=\frac{3}{4} \times 100 \%=75 \%$

Tabel 1. Hasil Perhitungan Confidence 2 Itemset

\begin{tabular}{|c|l|l|c|c|}
\hline No & Aturan Kode Produk & \multicolumn{1}{|c|}{ Kombinasi 2 Item } & Jumlah Transaksi & Confidence 50\% \\
\hline 1 & A1 dan A13 & $\begin{array}{l}\text { Bee Pollen Halus 100 gr dan Madu } \\
\text { Hitam 250 ml }\end{array}$ & 3 & $75 \%$ \\
\hline 2 & A1 dan A23 & $\begin{array}{l}\text { Bee Pollen Halus 100 gr dan Madu } \\
\text { Kaliandra 660 ml }\end{array}$ & 3 & $75 \%$ \\
\hline 3 & A13 dan A23 & $\begin{array}{l}\text { Madu Hitam 250 ml dan Madu } \\
\text { Kaliandra 660 ml }\end{array}$ & 3 & $75 \%$ \\
\hline
\end{tabular}

Minimun confidence yang ditentukan adalah 50\%, Hasilnya adalah 6 aturan asosiasi berdasarkan parameter yang telah di tentukan yaitu minimum support $8 \%$ dan minimum confidence $50 \%$, beberapa aturan atau Rule yang terbentuk, yaitu :

Jika konsumen membeli produk Bee Pollen Halus 100 gr maka akan membeli Madu Hitam 250 ml dengan nilai confidence $75 \%$.

Jika konsumen membeli produk Bee Pollen Halus 100 gr maka akan membeli Madu Kaliandra 660 ml dengan nilai confidence $75 \%$. Jika konsumen membeli produk Madu Hitam $250 \mathrm{ml}$ maka akan membeli Madu Kaliandra $660 \mathrm{ml}$ dengan nilai confidence 75\%. Jika konsumen membeli produk Madu Hitam $250 \mathrm{ml}$ maka akan membeli Bee Pollen Halus 100 gr dengan nilai confidence 75\%. Jika konsumen membeli produk Madu Kaliandra $660 \mathrm{ml}$ maka akan membeli Madu Hitam $250 \mathrm{ml}$ dengan nilai confidence 50\%. Jika konsumen membeli produk Madu Kaliandra $660 \mathrm{ml}$ maka akan membeli Bee Pollen Halus 100 gr dengan nilai confidence $50 \%$. 
Tabel 2. Aturan Asosiasi Confidence Minimum

\begin{tabular}{|c|l|c|c|c|}
\hline No & \multicolumn{1}{|c|}{ Rule } & Support & \multicolumn{2}{c|}{ Confidence } \\
\hline 1 & $\begin{array}{l}\text { Jika konsumen membeli Bee Pollen Halus 100 gr } \\
\text { maka akan membeli Madu Hitam 250 ml }\end{array}$ & $10,71 \%$ & $3 / 4$ \\
\hline 2 & $\begin{array}{l}\text { Jika konsumen membeli Bee Pollen Halus 100 gr } \\
\text { maka akan membeli Madu Kaliandra 660 ml }\end{array}$ & $10,71 \%$ & $3 / 4$ & $75 \%$ \\
\hline 3 & $\begin{array}{l}\text { Jika konsumen membeli Madu Hitam 250 ml maka } \\
\text { akan membeli Madu Kaliandra 660 ml }\end{array}$ & $10,71 \%$ & $3 / 4$ & $75 \%$ \\
\hline 4 & $\begin{array}{l}\text { Jika konsumen membeli Madu Hitam 250 ml maka } \\
\text { akan membeli Bee Pollen Halus 100 gr }\end{array}$ & $10,71 \%$ & $3 / 4$ & $75 \%$ \\
\hline 5 & $\begin{array}{l}\text { Jika konsumen membeli Madu Kaliandra } 660 \mathrm{ml} \\
\text { maka akan membeli Madu Hitam 250 ml }\end{array}$ & $10,71 \%$ & $3 / 6$ \\
\hline 6 & $\begin{array}{l}\text { Jika konsumen membeli Madu Kaliandra } 660 \mathrm{ml} \\
\text { maka akan membeli Bee Pollen Halus } 100 \mathrm{gr}\end{array}$ & $10,71 \%$ & $3 / 6$ & $50 \%$ \\
\hline
\end{tabular}

Tampilan Form algortima Apriori

1. Proses Apriori Itemset, setelah di klik tombol hitung maka akan muncul itemset 1 sampai itemset 2 dengan jumlah transaksi dan nilai support.

\begin{tabular}{|l|l|l|l}
\hline L1 (Large 1-itemset) & Item1 & Qty & Support \\
\hline 1 & madu kaliandra $660 \mathrm{ml}$ & 6 & $21.43 \%$ \\
\hline 2 & bee pollen halus $100 \mathrm{gr}$ & 4 & $14.29 \%$ \\
\hline 3 & madu hitam $250 \mathrm{ml}$ & 4 & $14.29 \%$ \\
\hline 4 & madu karet $300 \mathrm{ml}$ & 4 & 3 \\
\hline 5 & cuka madu $300 \mathrm{ml}$ & 3 & $14.29 \%$ \\
\hline 6 & madu super $300 \mathrm{ml}$ & 3 & $10.71 \%$ \\
\hline 7 & madu hitam $660 \mathrm{ml}$ & 3 & $10.71 \%$ \\
\hline 8 & madu mangga $170 \mathrm{ml}$ & 3 & $10.71 \%$ \\
\hline 9 & madu rambutan $300 \mathrm{ml}$ & 3 & $10.71 \%$ \\
\hline
\end{tabular}

2. Proses Apriori Itemset 2

Gambar 1. Proses Apriori Itemset 1

\begin{tabular}{|l|l|l|l|l|}
\hline \multicolumn{2}{|l|}{ 22(Large 2-itemset) } & Item2 & Qty & Support \\
\hline No & Item1 & madu kaliandra $660 \mathrm{ml}$ & 3 & $10.71 \%$ \\
\hline 1 & madu hitam $250 \mathrm{ml}$ & madu hitam $250 \mathrm{ml}$ & 3 & $10.71 \%$ \\
\hline 2 & bee pollen halus $100 \mathrm{gr}$ & madu kaliandra $660 \mathrm{ml}$ & 3 & $10.71 \%$ \\
\hline 3 & bee pollen halus $100 \mathrm{gr}$ & 3 & 3 \\
\hline
\end{tabular}

Gambar 2. Proses Apriori Itemset 2

3. Penentuan Aturan Asosiasi, hasil dari asosiasi atau hubungan setiap itemset dari itemset 2. 


\begin{tabular}{|c|c|c|c|c|c|c|}
\hline \multicolumn{7}{|c|}{ Asosiasi (2-itemset) } \\
\hline \multirow{2}{*}{ No } & \multirow{2}{*}{$\begin{array}{l}\text { Rule } \\
\text { Jika konsumen membeli madu hitam } 250 \mathrm{ml} \text { maka membeli madu kaliandra } 660 \mathrm{ml}\end{array}$} & \multirow{2}{*}{$\begin{array}{l}\text { Support } \\
10.71 \%\end{array}$} & \multicolumn{2}{|c|}{ Confidence } & \multirow{2}{*}{$\begin{array}{l}\text { Sup. * Conf. } \\
8.04\end{array}$} & \multirow{2}{*}{$\begin{array}{l}\text { Lift Ratio } \\
1.5\end{array}$} \\
\hline & & & $3 / 4$ & $75 \%$ & & \\
\hline 2 & Jika konsumen membeli bee pollen halus $100 \mathrm{gr}$ maka membeli madu hitam $250 \mathrm{ml}$ & $10.71 \%$ & $3 / 4$ & $75 \%$ & 8.04 & 1.5 \\
\hline 3 & Jika konsumen membeli bee pollen halus $100 \mathrm{gr}$ maka membeli madu kaliandra $660 \mathrm{ml}$ & $10.71 \%$ & $3 / 4$ & $75 \%$ & 8.04 & 1.5 \\
\hline 4 & Jika konsumen membeli madu hitam $250 \mathrm{ml}$ maka membeli bee pollen halus $100 \mathrm{gr}$ & $10.71 \%$ & $3 / 4$ & $75 \%$ & 8.04 & 1.5 \\
\hline 5 & Jika konsumen membeli madu kaliandra $660 \mathrm{ml}$ maka membeli madu hitam $250 \mathrm{ml}$ & $10.71 \%$ & $3 / 6$ & $50 \%$ & 5.36 & 1 \\
\hline 6 & Jika konsumen membeli madu kaliandra $660 \mathrm{ml}$ maka membeli bee pollen halus $100 \mathrm{gr}$ & $10.71 \%$ & $3 / 6$ & $50 \%$ & 5.36 & 1 \\
\hline
\end{tabular}

Gambar 3. Hasil Asosiasi Itemset

\section{Kesimpulan}

Kesimpulan penelitian :

1. Sistem dapat membantu Perusahaan dalam mengetahui hubungan (keterkaitan) antar produk menghasilkan aturan asosiasi berdasarkan nilai support dan nilai confidence.

2. Hasil perhitungan telah diuji dan perhitungan dari Aplikasi yang dibangun sesuai dengan perhitungan manual.

3. Dapat menghemat waktu dan mempermudah konsumen dalam membeli produk yang sering mereka beli karna letak produk yang bisa digabungkan disatu rak.

\section{Daftar Pustaka}

[1] A. J. P. Sibarani, "Implementasi Data Mining Menggunakan Algoritma Apriori Untuk Meningkatkan Pola Penjualan Obat," JATISI (Jurnal Tek. Inform. dan Sist. Informasi), vol. 7, no. 2, pp. 262-276, 2020.

[2] I. Wahyudi, S. Bahri, and P. Handayani, "Aplikasi Pembelajaran Pengenalan Budaya Indonesia," vol. V, no. 1, pp. 135-138, 2019.

[3] S. Aisyah and N. Normah, "Penerapan Algoritma Apriori Terhadap Data Penjualan Di Swalayan Koperasi Bappenas Jakarta Pusat," Paradig. - J. Komput. dan Inform., vol. 21, no. 2, pp. 235-242, 2019.

[4] J. S. Parapat and A. S. RMS, "Data Mining Klasifikasi Data Nasabah Kredit KSU Taman Mandiri Menggunakan Algoritma C4.5," J. Ilm. Tek. Elektro Komput. dan Inform., vol. 4, no. 2, p. 150, 2019.

[5] G. P. Utomo, A. Triayudi, and I. D. Sholihati, "Implementasi Algoritma Max-Miner Untuk Rekomendasi Produk Pada Restoran Kafe Lo Aja Implementation of the Max-Miner algorithm for product recommendations in Café Lo Aja," pp. 214-226, 2019.

[6] S. Al Syahdan and A. Sindar, "Data Mining Penjualan Produk Dengan Metode Apriori Pada Indomaret Galang Kota," J. Nas. Komputasi dan Teknol. Inf., vol. 1, no. 2, 2018.

[7] S. Butsianto and N. T. Mayangwulan, "Penerapan Data Mining Untuk Prediksi Penjualan Mobil Menggunakan Metode K-Means Clustering," J. Nas. Komputasi dan Teknol. Inf., vol. 3, no. 3, pp. 187$201,2020$.

[8] A. Ulumuddin et al., "Implementasi Data Mining Dengan Metode Association Rule Pada Aplikasi Business Analytic Data Penjualan," vol. 1, no. 3, pp. 1212-1218, 2018.

[9] K. K. Timba, "Penjualan Produk Elektronik Berbasis Web Pada Toko," vol. I, no. 01, pp. 10-15, 2020.

[10] A. K-means, M. Wahyudi, and L. Pujiastuti, "Penerapan Data Mining Dalam Mengelompokkan Data Pengangguran Terbuka Menurut Provinsi Menggunakan,” vol. 2, pp. 432-440, 2020.

[11] S. Devica, "Strategi Promosi Dengan Algoritma Fp-Groowth(Studi Kasus Di Universitas Harapan Medan)," nformation Technol. Comput. Sci., vol. 3, pp. 76-81, 2019.

[12] D. A. Rahmawati and K. Indriani, "Association Rule Mining Dengan Algoritma Apriori Untuk Penjualan Produk Verkol Lubricantes," Informatics Educ. Prof., vol. 2, no. 2, pp. 105-114, 2018.

[13] R. Buaton, D. Jollyta, H. Mawengkang, M. Zarlis, and S. Effendi, "Parameter Asosiasi Untuk Menentukan Korelasi Jurusan Dan Indeks Prestasi Kumulatif," J. Pilar Nusa Mandiri, vol. 15, no. 1, pp. 111-118, 2019. 